\title{
Anti-CD137 monoclonal antibodies and adoptive $T$ cell therapy: a perfect marriage?
}

\author{
Bettina Weigelin ${ }^{1} \cdot$ Elixabet Bolaños $^{2} \cdot$ Maria E. Rodriguez-Ruiz $^{2} \cdot$ \\ Ivan Martinez-Forero ${ }^{2} \cdot$ Peter Friedl $^{1} \cdot$ Ignacio Melero $^{2}$
}

Received: 16 October 2015 / Accepted: 25 February 2016 / Published online: 12 March 2016

(C) Springer-Verlag Berlin Heidelberg 2016

\begin{abstract}
CD137(4-1BB) costimulation and adoptive T cell therapy strongly synergize in terms of achieving maximal efficacy against experimental cancers. These costimulatory biological functions of CD137 have been exploited by means of introducing the CD137 signaling domain in clinically successful chimeric antigen receptors and to more efficiently expand $\mathrm{T}$ cells in culture. In addition, immunomagnetic sorting of CD137-positive T cells among tumor-infiltrating lymphocytes selects for the fittest antitumor $\mathrm{T}$ lymphocytes for subsequent cultures. In mouse models, co-infusion of both agonist antibodies and $\mathrm{T}$ cells attains marked synergistic effects that result from more focused and intense cytolytic activity visualized under in vivo microscopy and from more efficient entrance of $\mathrm{T}$ cells into the tumor through the vasculature. These several levels of dynamic interaction between adoptive $\mathrm{T}$ cell therapy and CD137 offer much opportunity to raise the efficacy of current cancer immunotherapies.
\end{abstract}

Keywords CD137 (4-1BB) - Adoptive T cell transfer · CARTs $\cdot$ Combined immunotherapy
Abbreviations
CAR Chimeric antigen receptor
CART Chimeric antigen receptor $\mathrm{T}$ cell
CTL Cytotoxic T lymphocyte
TIL Tumor-infiltrating lymphocyte

Ignacio Melero

imelero@unav.es

1 Department of Cell Biology, Radboud University Nijmegen Medical Centre, Nijmegen, The Netherlands

2 Centro de Investigación Médica Aplicada and Clinica Universidad de Navarra, University of Navarra, Avenida Pio XII, 55, 31008 Pamplona, Spain
Immunotherapy of cancer is living through a revolutionary period prompted by the extraordinary efficacy results of antibodies blocking CTLA-4 or PD-1/PD-L1 against a variety of solid cancers $[1,2]$. In parallel, durable clinical responses are achieved by adoptive $\mathrm{T}$ cell therapy against B cell lineage leukemias and lymphomas, using genetransduced $\mathrm{T}$ lymphocytes to express chimeric antigen receptors recognizing the B cell marker CD19 [3-5]. Very likely, significant additional benefit of innovative immunotherapy will result from combinatorial approaches $[1,2]$, as recently reported by combining anti-PD1- and anti-CTLA4-targeted therapy in a phase III clinical trial for metastatic melanoma patients [6] that was conducive to FDA approval. As yet clinically unexplored avenue, combining adoptive $\mathrm{T}$ cell therapy with immune-augmenting strategies could additionally increase the efficacy of immune control in solid tumors and improve outcome.

CD137 (4-1BB, tnfrsf9) is a surface receptor of the TNF receptor family that is expressed by activated but not resting $\mathrm{T}$ lymphocytes and NK cells [7]. Expression on $\mathrm{T}$ cells requires antigen recognition since it requires intense signaling through the antigen receptor complex. Therefore, only $\mathrm{T}$ cells that have been antigen-primed acquire the expression of CD137, the downstream signaling of which promotes $\mathrm{T}$ cell proliferation, memory differentiation, and effector functions and further prevents $\mathrm{T}$ cell apoptosis [8]. Under physiological circumstances, this receptor is ligated by CD137 ligand (4-1BB ligand), an agonist membrane molecule expressed by professional antigen-presenting cells, but also by some tumor cells. In order to exploit this pathway therapeutically, monoclonal antibodies which achieve much stronger, supraphysiological stimulation of CD137 signaling were designed to enhance costimulation of CD8 T lymphocytes and strongly improve the defense against syngeneic 

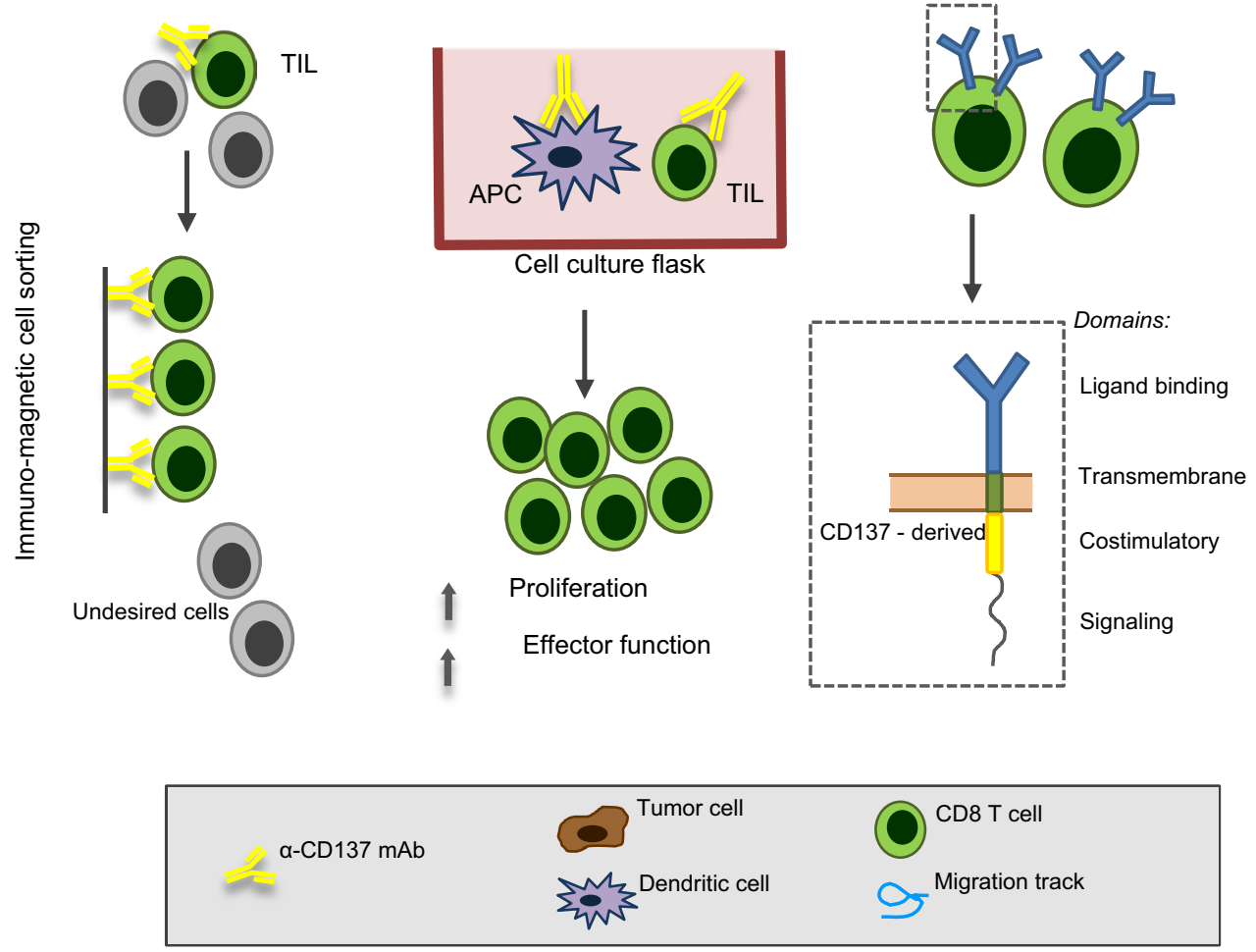

Fig. 1 Synergistic effects of $\alpha$-CD137 monoclonal antibodies and adoptive transfer of cytotoxic T lymphocytes. Selection, costimulation, and genetic engineering of tumor-specific CD8 T cells. Tumorinfiltrating lymphocytes (TIL) can be enriched ex vivo for CD137 expression to select for the potent antitumor $\mathrm{T}$ cells. Addition of

transplanted tumors [9]. Primarily, the mechanism of action is mediated by cytolytic T lymphocytes (CTLs) [9] which kill tumor cells in a perforin/granzyme-dependent fashion [10]. Recently, we have discovered a critical role for BATF-3-dependent dendritic cells in cross priming CTLs against tumor antigens for the efficacy of antiCD137 agonist monoclonal antibodies [11]. Direct and indirect effects of agonist anti-4-BB mAbs on regulatory $\mathrm{T}$ cells and susceptibility of effector $\mathrm{T}$ cells to regulatory $\mathrm{T}$ cells have been reported [12] even though the importance of such proposed mechanisms in CD137-based immunotherapy [13] remains to be fully elucidated.
anti-CD137 mAbs to ex vivo cultures further provides costimulation, enhancing $\mathrm{T}$ cell proliferation and effector function. Chimeric antigen receptors (CARs) containing the CD137 costimulatory domain show excellent antitumor efficacy in the clinic enhancing persistence and performance of the thus gene-engineered $\mathrm{T}$ lymphocytes

It has been shown in mouse models that anti-CD137 mAbs are synergistic with anti-PD-L1 and anti-OX40 immunostimulatory monoclonal antibodies against spontaneous tumors [14], as well as with adoptive $\mathrm{T}$ cell therapy [15]. Antihuman CD137 mAbs urelumab [16, 17] and PF-05082566 are being developed with interesting efficacy results as monotherapy $[18,19]$. As a potential caveat of application of urelumab, dose-dependent liver toxicity has resulted in a 10 -fold dose reduction relative to the maximum efficacious dose in early trials. Liver inflammation had been observed in mouse models [20] as a side effect that has taken place in humans as a life-threatening 
Activation of endothelial cells Enhanced CTL effector functions

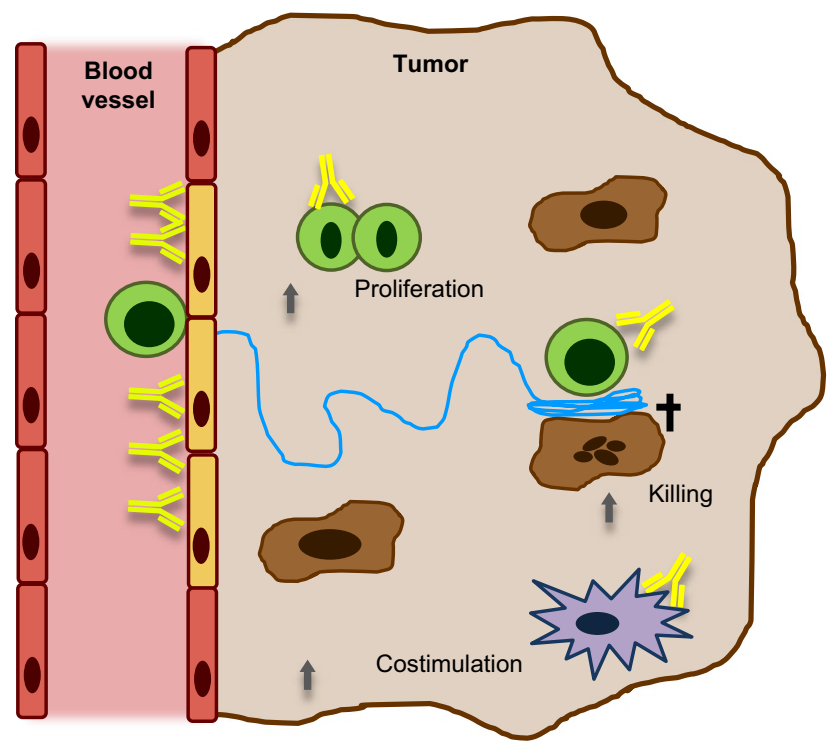

Fig. 2 Enhancement of effector functions in the tumor microenvironment. Blood vessel endothelial cells within the tumor lesion express CD137, and their activation by anti-CD137 mAb enhances adoptively transferred CD8 $\mathrm{T}$ cell extravasation at the tumor site. In the tumor microenvironment, anti-CD137 mAb enhances adoptively transferred CD8 $\mathrm{T}$ cell proliferation and survival and increases tumor-killing efficiency

dose-limiting toxicity in patients undergoing clinical trials at doses superior to $1 \mathrm{mg} / \mathrm{kg}$ of urelumab [16]. Of note, PF-05082566 dose escalation has been reported to be largely uneventful in terms of liver toxicity [19]. Therefore, to maximize efficacy and minimize side effects, combination therapy of urelumab is of prime interest, and realized in ongoing clinical trials combining anti-CD137 and antiPD-1 mAbs (NCT02253992, NCT02179918).

To consolidate the concept of anti-CD137 mAb-based immune augmentation, combined use with adoptive $\mathrm{T}$ cell therapy is particularly attractive, based on four lines of synergistic mechanisms (Figs. 1 and 2):

1. CD137 expression allows for the selection of the best fitted $T$ cells among cultures of tumor-infiltrating lymphocytes. Immunomagnetic sorting can be applied to retrieve and concentrate these lymphocytes for further culture, thereby selecting for lymphocytes with antitumor activity $[21,22]$.

2. Culture in the presence of the antibody used for selection conditions and stimulates the $\mathrm{T}$ cells so the yield of the cultures is more abundant while showing better antitumor performance upon subsequent adoptive $\mathrm{T}$ cell transfer in mouse models of cancer [23, 24]. Addition of 4-1BB agonist antibodies when expanding TIL or CAR $\mathrm{T}$ cells increases both quantitative yield and qualitative cytolytic capacity on a per-cell basis.

3. Administration of anti-CD137 mAbs to mice which had been TIL adoptively transferred results in synergistic effects. This is mainly mediated by costimulation of the infused $\mathrm{T}$ lymphocytes [25], but also by enhancing $\mathrm{T}$ cell entry into malignant tissue through a direct proinflammatory effect on tumor-associated endothelial cells that ectopically express CD137 [26].

4. It has been shown that in the CAR constructs based on single-chain antibodies linked to intracellular signaling domains of $\mathrm{CD} 3 \zeta$, those bearing the costimulatory intracellular domain of CD137 have the greatest antitumor immunity. Indeed, the most successful trials based on adoptive transfer of CAR transduced T cells incorporate the intracellular domain of CD137 [4, 27].

We have recently reported [28] synergistic immune effects using intravital time-lapse two-photon microscopy of adoptively transferred tumor-specific CD8 T cells infiltrating B16F10 melanomas in the absence or presence of anti-CD137 agonist antibodies (Fig. 2). Using tumor cells marked with a fluorescent histone and using genetically fluorescent $\mathrm{T}$ cells, we are able to obtain dynamic estimates of the migration and tumor-killing as well as mitosis and apoptosis rates of the transferred $\mathrm{T}$ cells and melanoma cells (Fig. 3). In this synergistic experimental setting, the behavior of cytotoxic $\mathrm{T}$ cells is modified under the influence of anti-CD137 mAbs, so T cells exert more focused activity against the tumor cells, with (1) improved tumor infiltration capability based on enhanced migration and (2) prolonged engagement with tumor cells followed by apoptosis induction. Clues from these experiments are important to guide clinical trials of combination approaches. Caution is needed since the mechanisms accounting for side effects of adoptive $\mathrm{T}$ cell therapy and its preconditioning regimens can interact with those of anti-CD137 mAbs leading 

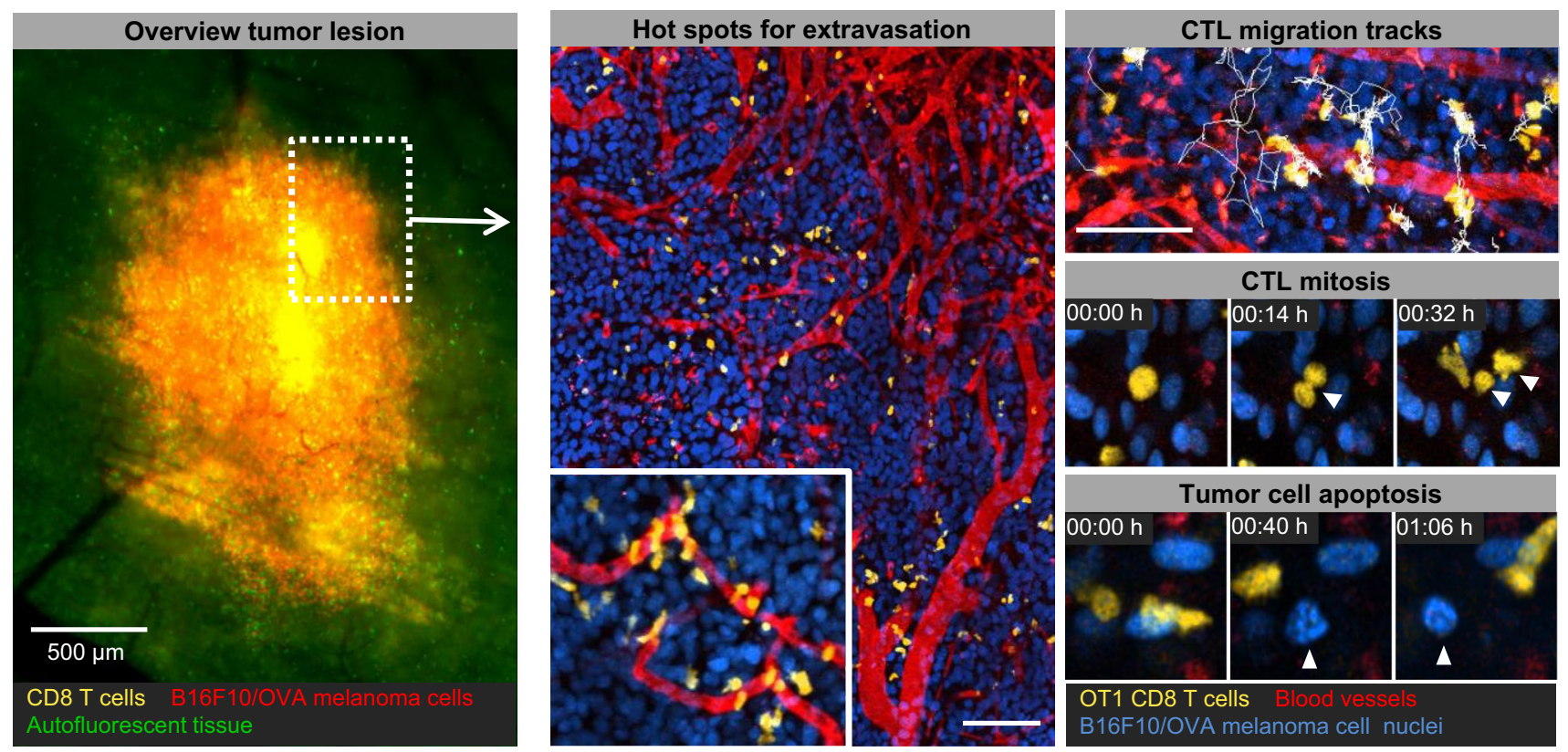

Fig. 3 Intravital imaging to monitor therapy response. Intravital imaging allows to image tumor growth dynamics and therapy response over time and in relation to adoptively transferred CD8 T cell extravasation and tumor infiltration patterns. 3D reconstruction at subcellular resolution and time-lapse recordings captures the dynamics of $\mathrm{T}$ cell effector function and allows quantification of therapeutic response at the single-cell level. The images show dynamic multiphoton microscopy of a B16F10/OVA melanoma implanted in the

to serious adverse events. The overall picture so far is that there are important exploitable synergistic mechanisms between adoptive $\mathrm{T}$ cell transfer and immunostimulatory mAbs.

Acknowledgments We acknowledge fruitful scientific discussions with Drs. Lasarte, Hervas, Quetglas, Alfaro, and Inoges. Financial support was from Ministerio de Economia (SAF2008-03294 and SAF2011-22831 to Ignacio Melero). Ignacio Melero was also funded by the Departamento de Salud del Gobierno de Navarra, redes temáticas de investigación cooperativa (RD06/0020/0065), European Commission 7th framework program (ENCITE and IACT) and European Union Horizon 2020 (PROCROP). Peter Friedl was funded by the Dutch Cancer Foundation (KWF 2008-4031), the Cancer Genomics Center Netherlands, and FP7 of the European Union (ENCITE HEALTH TH-15-2008-208142).

\section{Compliance with ethical standards}

Conflict of interest Ignacio Melero has served as a consultant for Bristol Myers Squibb, Incyte, AstraZeneca, Roche-Genentech, Boehringer Ingelheim. All the other authors declare no conflict of interest.

\section{References}

1. Melero I, Berman DM, Aznar MA, Korman AJ, Gracia JL, Haanen J (2015) Evolving synergistic combinations of targeted mouse dermis and treated with combined anti-CD137 mAb and adoptive transfer of fluorescent TCR transgenic CD8 T cells recognizing a surrogate tumor antigen. These photographs represent an area of the tumor imaged at cell size resolution in these time-lapse experiments, contrasted blood vessels and fluorescent transgenic T cells and observable functional events on T lymphocytes under the influence of CD137 costimulation (Weigelin et al. [28] unpublished observations). Scale bar $100 \mu \mathrm{m}$

immunotherapies to combat cancer. Nat Rev Cancer 15:457472. doi: $10.1038 / \mathrm{nrc} 3973$

2. Sharma P, Allison JP (2015) Immune checkpoint targeting in cancer therapy: toward combination strategies with curative potential. Cell 161:205-214. doi:10.1016/j.cell.2015.03.030

3. Maus MV, Fraietta JA, Levine BL, Kalos M, Zhao Y, June CH (2014) Adoptive immunotherapy for cancer or viruses. Annu Rev Immunol 32:189-225. doi:10.1146/ annurev-immunol-032713-120136

4. Kalos M, Levine BL, Porter DL, Katz S, Grupp SA, Bagg A, June CH (2011) T cells with chimeric antigen receptors have potent antitumor effects and can establish memory in patients with advanced leukemia. Sci Transl Med 3:95ra73. doi:10.1126/ scitranslmed.3002842

5. Garfall AL, Maus MV, Hwang WT et al (2015) Chimeric antigen receptor T cells against CD19 for multiple myeloma. N Engl J Med 373:1040-1047. doi:10.1056/NEJMoa1504542

6. Larkin J, Chiarion-Sileni V, Gonzalez R et al (2015) Combined nivolumab and ipilimumab or monotherapy in untreated melanoma. N Engl J Med 373:23-34. doi:10.1056/NEJMoa1504030

7. Melero I, Hirschhorn-Cymerman D, Morales-Kastresana A, Sanmamed MF, Wolchok JD (2013) Agonist antibodies to TNFR molecules that costimulate $\mathrm{T}$ and NK cells. Clin Cancer Res 19:1044-1053. doi:10.1158/1078-0432.CCR-12-2065

8. Vinay DS, Kwon BS (2014) 4-1BB (CD137), an inducible costimulatory receptor, as a specific target for cancer therapy. BMB Rep. 47:122-129

9. Melero I, Shuford WW, Newby SA, Aruffo A, Ledbetter JA, Hellstrom KE, Mittler RS, Chen L (1997) Monoclonal antibodies against the 4-1BB T-cell activation molecule eradicate established tumors. Nat Med 3:682-685 
10. Morales-Kastresana A, Catalan E, Hervas-Stubbs S, Palazon A, Azpilikueta A, Bolanos E, Anel A, Pardo J, Melero I (2013) Essential complicity of perforin-granzyme and FAS-L mechanisms to achieve tumor rejection following treatment with anti-CD137 mAb. J Immunother Cancer. 1:3. doi:10.1186/2051-1426-1-3

11. Sanchez-Paulete AR, Cueto FJ, Martinez-Lopez M et al (2015) Cancer immunotherapy with immunomodulatory anti-CD137 and anti-PD-1 monoclonal antibodies requires Batf3-dependent dendritic cells. Cancer Discov. 6:71-79. doi:10.1158/2159-8290. CD-15-0510

12. So T, Lee SW, Croft M (2008) Immune regulation and control of regulatory T cells by OX40 and 4-1BB. Cytokine Growth Factor Rev 19:253-262. doi:10.1016/j.cytogfr.2008.04.003

13. Kim YH, Choi BK, Oh HS, Kang WJ, Mittler RS, Kwon BS (2009) Mechanisms involved in synergistic anticancer effects of anti-4-1BB and cyclophosphamide therapy. Mol Cancer Ther 8:469-478. doi:10.1158/1535-7163.MCT-08-0993

14. Morales-Kastresana A, Sanmamed MF, Rodriguez I et al (2013) Combined immunostimulatory monoclonal antibodies extend survival in an aggressive transgenic hepatocellular carcinoma mouse model. Clin Cancer Res 19:6151-6162. doi:10.1158/1078-0432.CCR-13-1189

15. May KF Jr, Chen L, Zheng P, Liu Y (2002) Anti-4-1BB monoclonal antibody enhances rejection of large tumor burden by promoting survival but not clonal expansion of tumor-specific CD8 + T cells. Cancer Res 62:3459-3465

16. Ascierto PA, Simeone E, Sznol M, Fu YX, Melero I (2010) Clinical experiences with anti-CD137 and anti-PD1 therapeutic antibodies. Semin Oncol 37:508-516. doi:10.1053/j. seminoncol.2010.09.008

17. Sznol M, Hodi FS, Margolin K, McDermott DF, Ernstoff MS, Kirkwood JM, Wojtaszek C, Feltquate D, Logan T (2008) Phase I study of BMS-663513, a fully human anti-CD137 agonist monoclonal antibody, in patients (pts) with advanced cancer (CA). J Clin Oncol. 26. Abstract 3007

18. Fisher TS, Kamperschroer C, Oliphant T et al (2012) Targeting of 4-1BB by monoclonal antibody PF-05082566 enhances T-cell function and promotes anti-tumor activity. Cancer Immunol Immunother 61:1721-1733. doi:10.1007/s00262-012-1237-1

19. Gopal AK, Bartlett NL, Levy R et al (2015) A phase I study of PF-05082566 (anti-4-1BB) + rituximab in patients with CD20 + NHL. J Clin Oncol. 33. Abstract 3004

20. Dubrot J, Milheiro F, Alfaro C et al (2010) Treatment with antiCD137 mAbs causes intense accumulations of liver T cells without selective antitumor immunotherapeutic effects in this organ.
Cancer Immunol Immunother 59:1223-1233. doi:10.1007/ s00262-010-0846-9

21. Wolfl M, Kuball J, Ho WY, Nguyen H, Manley TJ, Bleakley M, Greenberg PD (2007) Activation-induced expression of CD137 permits detection, isolation, and expansion of the full repertoire of CD8 + T cells responding to antigen without requiring knowledge of epitope specificities. Blood 110:201-210. doi:10.1182/ blood-2006-11-056168

22. Gros A, Robbins PF, Yao X et al (2014) PD-1 identifies the patient-specific $\mathrm{CD} 8(+)$ tumor-reactive repertoire infiltrating human tumors. J Clin Invest. 124:2246-2259. doi:10.1172/ JCI73639

23. Chacon JA, Wu RC, Sukhumalchandra P, Molldrem JJ, Sarnaik A, Pilon-Thomas S, Weber J, Hwu P, Radvanyi L (2013) Costimulation through 4-1BB/CD137 improves the expansion and function of $\mathrm{CD} 8(+)$ melanoma tumor-infiltrating lymphocytes for adoptive T-cell therapy. PLoS ONE 8:e60031. doi:10.1371/ journal.pone. 0060031

24. Maus MV, Thomas AK, Leonard DG, Allman D, Addya K, Schlienger K, Riley JL, June CH (2002) Ex vivo expansion of polyclonal and antigen-specific cytotoxic $\mathrm{T}$ lymphocytes by artificial APCs expressing ligands for the T-cell receptor, CD28 and 4-1BB. Nat Biotechnol 20:143-148. doi:10.1038/nbt0202-143

25. Hernandez-Chacon JA, Li Y, Wu RC, Bernatchez C, Wang Y, Weber JS, Hwu P, Radvanyi LG (2011) Costimulation through the CD137/4-1BB pathway protects human melanoma tumorinfiltrating lymphocytes from activation-induced cell death and enhances antitumor effector function. J Immunother 34:236-250. doi:10.1097/CJI.0b013e318209e7ec

26. Palazon A, Teijeira A, Martinez-Forero I et al (2011) Agonist anti-CD137 mAb act on tumor endothelial cells to enhance recruitment of activated T lymphocytes. Cancer Res 71:801-811. doi:10.1158/0008-5472.CAN-10-1733

27. Carpenito C, Milone MC, Hassan R et al (2009) Control of large, established tumor xenografts with genetically retargeted human T cells containing CD28 and CD137 domains. Proc Natl Acad Sci U S A 106:3360-3365. doi:10.1073/pnas.0813101106

28. Weigelin B, Bolanos E, Teijeira A et al (2015) Focusing and sustaining the antitumor CTL effector killer response by agonist anti-CD137 mAb. Proc Natl Acad Sci U S A 112:7551-7556. doi:10.1073/pnas.1506357112 